\title{
9.04
}

\section{Saber o no saber... Derecho e información genética}

\author{
To know or not to know... Law and genetic information
}

\section{José Ignacio Solar Cayón}

Profesor titular de Filosofía del Derecho. Universidad de Cantabria. Santander, España.

Resumen: El extraordinario desarrollo de las técnicas genéticas, con su formidable capacidad de afectación a la autonomía personal y de invasión de los derechos individuales, está teniendo un impacto profundo en el pensamiento jurídico, obligándonos a revisar algunos de los presupuestos en que se funda nuestra concepción de los derechos fundamentales. Así, el reconocimiento del derecho del individuo a no conocer sus datos genéticos parece desafiar nociones esenciales como las de autonomía y racionalidad del sujeto de derechos, vinculadas en el proyecto ilustrado de emancipación del individuo a la idea de pleno acceso al conocimiento. Sin embargo, la propia idea de "ignorancia" no resulta ajena al discurso de fundamentación de los derechos fundamentales, como prueba el papel esencial que el "velo de la ignorancia" desempeña en la revisión de la tradición liberal efectuada por John Rawls. A partir de la teoría de éste y de John Stuart Mill se indaga en los fundamentos filosóficos del derecho a no saber los datos genéticos y en sus límites, ante la existencia de posibles derechos de terceros a acceder a esa información. Asimismo, se pone de manifiesto el papel que en este nuevo contexto juega el Derecho como instancia administradora del conocimiento y de la ignorancia, ante la amenaza de un determinismo genético que parece poner en cuestión en última instancia la idea misma de libertad individual.

Palabras clave: información genética; derecho a no saber; autonomía; racionalidad; ignorancia.

Key-words: genetic information, right not to know, autonomy, rationality, ignorance.

\section{La singularidad de la información genética y su impacto en el pensamiento jurídico.}

Las informaciones relativas a la salud de un individuo y sus decisiones en este ámbito conciernen a la esfera más íntima de su personalidad. De ahí que los datos de carácter personal sobre la salud se configuren en los instrumentos jurídicos internacionales y nacionales como datos especialmente protegidos cuyo tratamiento, 
en aras a la salvaguarda de los derechos del paciente a la intimidad y a la confidencialidad, se halla sujeto a especiales condiciones y garantías. Y también que, a fin de posibilitar que el paciente pueda tomar de manera responsable y consciente las decisiones relativas a su salud, se garantice su derecho a recibir una información suficiente y adecuada.

Esta necesidad de proteger los datos de carácter personal y de garantizar que las decisiones del paciente sean tomadas de manera consciente y responsable se hace especialmente acusada cuando nos movemos específicamente en el dominio de los datos y las pruebas genéticas. La información genética presenta unas características sumamente especiales que la singularizan respecto del resto de las informaciones relativas a la salud. Esta información tiene un carácter permanente; afecta al núcleo más íntimo de la propia identidad personal, en cuanto da cuenta de aquellos rasgos únicos e irrepetibles que constituyen la base de la individualización y que condicionan en gran medida el resto de los rasgos biológicos; al mismo tiempo, trasciende la dimensión meramente individual, aportando información relevante acerca del grupo familiar y étnico; desvela aspectos ocultos de nuestra constitución física y de nuestra salud; encierra las claves de nuestro origen biológico; posee un enorme potencial predictivo en relación a las predisposiciones y la salud futura del sujeto y de su descendencia; y es susceptible, por el enorme potencial de desarrollo de las técnicas en este ámbito, de usos e investigaciones cuyas posibilidades se desconocen en el momento de la realización de las pruebas o de la recogida de datos. Estas características dotan a la información genética de una relevancia jurídica especial por su extraordinaria capacidad de afectación a la autonomía del sujeto y por el impacto potencialmente discriminatorio e invasivo de los derechos individuales que puede acarrear su incorrecta utilización ${ }^{1}$. Además, estos riesgos, inherentes a la propia naturaleza de la información genética, se ven acrecentados por hechos como los extraordinarios avances en genómica, la utilización en proyectos de investigación de los biobancos, la difusión a través de Internet de los tests genéticos directos al

\footnotetext{
${ }^{1}$ Como señala Malem (2005, p. 100) "la investigación genética incrementa nuestra información y, en consecuencia, aumenta la posibilidad de ejercer nuestra autonomía de forma exitosa". Pero, "al mismo tiempo, esa información en manos de terceros vuelve a los hombres y mujeres seres transparentes, casi sin secretos, y, en ese sentido, vulnerables ante los demás". Y ello "afecta negativamente, por cierto, también nuestra autonomía y el ejercicio de nuestros derechos".
} 
consumidor o el desarrollo de la bioinformática, que hacen ineficaces las tradicionales protecciones de la autonomía e intimidad del sujeto ${ }^{2}$.

Estos aspectos singulares de la información genética han sido explícitamente reconocidos en el artículo 4 de la Declaración Internacional sobre los Datos Genéticos Humanos, promulgada por la UNESCO en 2003. Artículo que, en atención a dicha singularidad, exige prestar "la debida atención al carácter sensible de los datos genéticos humanos e instituir un nivel de protección adecuado de esos datos y de las muestras biológicas". De esta manera encuentra respaldo en dicha Declaración la creciente tendencia, tanto a nivel nacional como internacional, de otorgar un régimen jurídico específico, de protección reforzada, a los datos genéticos, lo que conduce a la introducción de particularidades en el régimen general de determinadas instituciones o sectores jurídicos.

En este sentido, podríamos hablar de la exigencia de un régimen de garantías más estricto para la conservación de muestras genéticas y de perfiles de ADN en ficheros policiales que para la conservación de huellas digitales $u$ otro tipo de datos identificativos, en razón de la especial gravedad de la "intrusión genética"3. De la admisión en el ámbito de la información genética de limitaciones y restricciones especiales al derecho del paciente a la intimidad y a la confidencialidad, en aras a la necesidad de garantizar los derechos de los familiares que pudieran tener interés en aquella información. De la redefinición que está sufriendo la institución del consentimiento informado y específico - especialmente a raíz del desarrollo de los biobancos - ante la incapacidad de las tradicionales garantías de la confidencialidad para proteger la intimidad genética del sujeto, admitiéndose progresivamente en diversas legislaciones nacionales la prestación de un consentimiento ampliado de carácter más genérico o abierto ${ }^{4}$. 0 de la preponderancia otorgada en legislaciones como la española a los principios de respeto a la voluntad de las partes y de responsabilidad como determinantes para la determinación de la filiación en el caso de los hijos nacidos mediante técnicas de reproducción asistida con gametos de

${ }^{2}$ Cfr. Macklin (2011, p. 32-35) sobre la práctica imposibilidad de garantizar hoy una confidencialidad absoluta en este campo.

${ }^{3} \mathrm{Cfr}$. las decisiones del Tribunal Europeo de Derechos Humanos en los casos Van der Velden c. Holanda (2006) y Marper c. Reino Unido (2008).

4 Esta posibilidad está reconocida en textos internacionales como la Guía de la OCDE de 2009 sobre biobancos y bases de datos de investigación en genética humana (art. 6). En el plano nacional, Reino Unido, Alemania, Australia, Suiza, Japón, Islandia, Estonia e incluso España admiten ya, con diverso alcance y diferentes requisitos, alguna forma de este tipo de consentimiento (Kosseim y Jospe, 2011, p. 137-154). 
donantes, excepcionándose así el régimen general basado en el principio de la verdad biológica. Todas ellas constituyen transformaciones y modulaciones operadas en distintos sectores jurídicos en razón de la singularidad de los datos genéticos.

Pero, más allá de tales cambios legislativos, este "excepcionalismo genético" está originando una revolución más profunda en nuestros modos habituales de pensamiento. Es una realidad que la continua ampliación de los conocimientos acerca de la constitución de nuestra personalidad y de las posibilidades de intervención en la misma que ofrecen los constantes desarrollos tecnológicos en este ámbito están modificando algunas de las condiciones y de los presupuestos sobre los que se asientan importantes pautas de nuestro pensamiento, obligándonos a cuestionar y redefinir nuestros criterios de actuación. En el año 2009 la revista Time seleccionó a los biobancos como una de las diez ideas que están cambiando el mundo. Sin duda, la genética está cambiando la manera de prevenir, diagnosticar y tratar enfermedades, pero también - y no sólo en relación al ámbito estrictamente sanitario - está transformando nuestra forma de afrontar algunas de las principales cuestiones sociales, éticas y jurídicas vinculadas a la propia existencia humana.

El pensamiento y la teoría jurídica no podían permanecer, pues, ajenos a esta situación, particularmente en el ámbito de la teoría de los derechos fundamentales. La singularidad de la información genética y la consecuente necesidad de otorgar al individuo una protección específica y reforzada en este campo nos está obligando a someter a revisión algunos de los presupuestos fundamentales sobre los que se asienta el paradigma vigente de justificación y fundamentación de los derechos humanos. En este sentido cabe mencionar, por ejemplo, el debate surgido en relación al problema de la determinación del sujeto del derecho a la intimidad en el ámbito de los datos genéticos, que desafía el presupuesto de la titularidad individual de los derechos fundamentales. Dada la naturaleza compartida de la información genética, son crecientes las voces que apuntan a la necesidad de que el Derecho otorgue entidad jurídica a la noción de familia genética como sujeto unitario, argumentando que la información genética no es propiedad del individuo sino patrimonio común del grupo familiar. De este modo, afirma Stefano Rodotà (2001, p. 673), ante los datos genéticos ya obtenidos de un sujeto, el acceso a los mismos por parte de un familiar consanguíneo no implicaría una vulneración del derecho a la intimidad de aquel porque el familiar no estaría accediendo a datos de un tercero sino a datos 
personales propios. Incluso, de manera más general, ante las profundas transformaciones operadas por los recientes desarrollos científicos y tecnológicos en el ámbito de la biomedicina y su impacto en los derechos de la personalidad, hay quienes señalan que estamos asistiendo al alumbramiento de una nueva generación de derechos fundamentales ${ }^{5}$.

En este contexto, mi atención se centrará en una especificidad del régimen jurídico de la información genética que ha generado un interesante debate acerca de su compatibilidad o encaje en el paradigma vigente de los derechos fundamentales. Me refiero al reconocimiento del derecho del individuo a no conocer sus datos genéticos. No puede desconocerse que el extraordinario potencial predictivo de los análisis genéticos conlleva siempre el riesgo, para quien se somete a ellos, de hacer frente a descubrimientos inesperados que pueden alterar sustancialmente su perspectiva vital (y la de su familia) ${ }^{6}$. El carácter permanente de la información genética, la imposibilidad en muchos casos de reducir los riesgos de padecer en el futuro la enfermedad detectada o de trasmitirla a los descendientes, la carencia de un tratamiento efectivo para la misma (aunque es posible diagnosticar el $95 \%$ de las enfermedades genéticas más habituales, sólo se dispone de tratamiento para un reducido número de ellas), e incluso el posible carácter estigmatizador de la información, son, sin duda, factores que pueden tener un profundo impacto psicológico sobre el individuo, afectando muy negativamente a su capacidad de decisión y, en definitiva, a sus relaciones familiares y sociales.

Por ello, no resulta extraño que haya sido en este ámbito de los datos genéticos donde se ha planteado con especial fuerza la legitimidad del derecho del individuo a desconocerlos. Sin embargo, desde una perspectiva teórica, afirmar la existencia de este derecho parece-al menos en una primera impresión- contrariar alguno de los presupuestos sobre los que se funda la misma noción de "derechos fundamentales". Particularmente, aquella premisa del sujeto de derecho como un agente autónomo y racional que constituye su soporte antropológico.

\footnotetext{
${ }^{5}$ En opinión de Gómez Sánchez (2007, p. 227-234), esta nueva generación estaría constituida por un conjunto de derechos nuevos y de derechos ya reconocidos, pero redefinidos o reinterpretados a la luz de las nuevas condiciones y exigencias, que conformarían un nuevo estatuto jurídico de la vida humana.

${ }^{6}$ Como afirma L. Sagols (2007, p. 487), "los datos genéticos han permitido pasar del paradigma de la curación al de la predicción".
} 


\section{El derecho a no recibir información genética.}

\subsection{Autonomía, racionalidad e ignorancia: sobre los fundamentos filosóficos de un derecho a no saber.}

El derecho a no conocer los datos genéticos ha sido expresamente reconocido en diversos instrumentos jurídicos internacionales relativos al ámbito de la biomedicina. Así, el artículo 10 del Convenio Europeo de Derechos Humanos y Biomedicina, adoptado en la ciudad española de Oviedo en 1997, después de reconocer el derecho de toda persona a conocer cualquier información obtenida respecto a su salud, expresa que "no obstante, deberá respetarse la voluntad de una persona a no ser informada". En parecidos términos, la Declaración Universal sobre el Genoma Humano y los Derechos Humanos, del mismo año, afirma en su artículo 5 que "se debe respetar el derecho de toda persona a decidir que se le informe o no de los resultados de un examen genético y de sus consecuencias". Y el mismo ha sido recogido también en la Declaración Internacional sobre Datos Genéticos Humanos de 2003 (art. 10). A la estela de este amplio reconocimiento en el Derecho internacional, un número creciente de Estados han ido incorporando este derecho en sus legislaciones. En el ordenamiento jurídico español este reconocimiento se produjo inicialmente en el art. 4.1 de la Ley 41/2002 básica reguladora de la autonomía del paciente y de derechos y obligaciones en materia de información y documentación clínica, y, posteriormente, ha sido reafirmado en el artículo 4.5 de la Ley 14/2007 de investigación biomédica.

Sin embargo, paralelamente a este progresivo reconocimiento legal se ha generado un importante debate acerca de sus fundamentos éticos y jurídicos ${ }^{7}$. La pretensión del reconocimiento de un derecho a no saber suena extraña o paradójica en el marco de nuestra filosofía de los derechos fundamentales. Y, de hecho, dicha pretensión ha sido rechazada por una parte de la doctrina apelando al carácter inherentemente irracional de tal derecho. Básicamente, los defensores de esta posición, que parten de una concepción de la autonomía vinculada ineludiblemente a la idea de racionalidad, argumentan que el rechazo del individuo a recibir una información cuyo conocimiento sería beneficioso para él, en cuanto le permitiría una toma más racional de sus decisiones, no podría considerarse una decisión autónoma

\footnotetext{
${ }^{7}$ Para una condensada pero interesante exposición de los principales argumentos esgrimidos a favor y en contra del reconocimiento de este Derecho, ver Chadwick, 1997, p. 13- 22.
} 
porque carece de aquella condición necesaria para el ejercicio de la autonomía personal. Desde este punto de vista, la decisión de ignorar ciertos hechos que le permitirían tomar sus decisiones de una manera más informada y, en definitiva, racional constituiría un menoscabo de la autonomía individual.

Sin duda, en una primera impresión, la propia noción de un derecho a la ignorancia resulta contraintuitiva - casi un contrasentido - en el seno de un sistema edificado sobre el presupuesto de la autonomía del sujeto como agente racional. Especialmente si consideramos el proceso histórico que conduce a la construcción de la propia idea de "derechos humanos". En dicho proceso, que tiene lugar en Europa entre los siglos XVI y XVIII, resulta prácticamente imposible desligar -o siquiera distinguir- la lucha por la liberación política del individuo de su lucha por la libertad de conocimiento, en cuanto su objetivo es la emancipación integral del individuo frente a toda autoridad dogmática, ya sea ésta de carácter político, religioso, intelectual o de cualquier otro tipo. El proyecto ilustrado no puede concebir uno de estos aspectos sin el otro en la medida en que, desde su perspectiva, no se trata de cuestiones distintas sino de dos facetas interdependientes de un mismo ideal: la liberación del individuo de cualquier paternalismo en virtud de su capacidad para tomar decisiones de manera autónoma y racional en cualquier ámbito de su vida. Por eso, toda teoría política implica una epistemología. Así, la publicación del Segundo Tratado sobre el Gobierno Civil de Locke, en el que éste - en respuesta al Patriarca de Filmer desarrolla su teoría de los derechos naturales del hombre, sentando las bases del liberalismo político, va acompañada de la publicación de su Ensayo sobre el Entendimiento Humano, sobre los modos de adquirir el conocimiento. Y, del mismo modo, tampoco puede desligarse el Contrato Social de Rousseau de la pedagogía del Emilio o la teoría política de Kant de su Crítica de la Razón Pura.

Tan indisoluble es esta relación que, a los ojos de este último, el significado genuino y radical del proyecto ilustrado se encierra en aquel grito de Sapere aude! (¡Atrévete a saber!), cuya exhalación marca el momento de la salida de la minoría de edad del individuo (Kant, 1989, p. 17). Este es, pues, el sustrato filosófico y antropológico que se encuentra detrás de las Declaraciones de Derechos: un sujeto racional y decidido a afrontar su existencia haciendo uso de su propio entendimiento. Así como la mente del hombre se presenta en la epistemología liberal como un papel en blanco que sólo puede ser rellenado a través del conocimiento adquirido mediante 
el esfuerzo personal, y en íntima relación con ello, su destino vital se presenta también para el ilustrado como un proyecto totalmente abierto que aquel debe construir a partir del ejercicio responsable de su libertad.

Además, esta afirmación de un derecho a no saber resulta especialmente chocante en el ámbito sanitario. Constituye sin duda éste uno de los espacios de micropoder que más tenazmente se ha resistido a la emancipación del individuo de tutelas paternalistas, habiéndose articulado hasta tiempos muy recientes a partir de una relación médico-paciente en la que el profesional sanitario, en virtud de su superior estatus epistemológico, se constituía en administrador plenipotenciario de la información. Por ello, también en este ámbito - o, más bien, sobre todo en este ámbito - la lucha por el reconocimiento de los derechos del paciente ha sido fundamentalmente una lucha por su acceso al conocimiento. Para apoyar tal afirmación basta con recordar la ingente literatura generada en los últimos años en torno a la cuestión del "consentimiento informado" y la posición central asignada hoy a dicha institución en la estrategia de protección de los derechos del paciente. El derecho de éste a ser informado - y el correlativo deber del profesional sanitario de informar - de su estado de salud y de los potenciales riesgos y beneficios de un tratamiento o de una intervención constituye la garantía fundamental que posibilita la autonomía del paciente y su toma racional de decisiones. Sin embargo, paradójicamente, apenas recién conquistado el derecho a conocer, el Derecho ha de afrontar la pretensión, en sentido inverso, de reconocimiento de un derecho a no saber.

Pese a tales paradojas y perplejidades, sin embargo, podemos preguntarnos si también en relación con la cuestión planteada podemos - como hace Garzón Valdés (1999, p. 129) con carácter general - "rescatar algunas formas de ignorancia que tal vez respondan más a nuestra manera de ser y a nuestro propósito de actuar racionalmente en sociedad" que el conocimiento de determinadas circunstancias. ${ }^{8} \mathrm{Y}$, en este sentido, apenas basta una reflexión un poco más detenida para darnos cuenta de que la opción por el no conocimiento no resulta tan extraña como pudiera parecer en principio, ni siquiera en el marco de la reflexión filosófica sobre la fundamentación de los derechos humanos.

\footnotetext{
${ }^{8}$ En este interesante artículo el autor establece una clasificación de los distintos tipos de ignorancia, defendiendo el valor positivo de algunos de ellos.
} 
Ante aquella pregunta, el filósofo del Derecho inmediatamente rememorará el papel esencial que el "velo de la ignorancia" desempeña en la revisión realizada por Rawls de las teorías contractualistas clásicas de Locke, Rousseau y Kant. Recordemos que en la versión rawlsiana del contrato social los sujetos que han de consensuar los principios de justicia que regirán la sociedad (que, significativamente, no son individuos sino líneas genéticas, a fin de tener debidamente en cuenta los intereses de las diversas generaciones) se encuentran en una situación hipotética peculiar, caracterizada fundamentalmente por el hecho de que desconocen las condiciones o circunstancias particulares de su existencia. Si bien en esta "posición original", a partir de la cual ha de desarrollarse la deliberación para decidir la distribución social de los derechos y deberes, los sujetos poseen toda la información necesaria acerca de los hechos generales que afectan a la elección de los principios de justicia, ignoran todos los hechos acerca de su propia persona y del lugar que ocupan en la sociedad (talentos y capacidades naturales, rasgos psicológicos, raza, religión, concepción del bien, proyecto de vida, posición o clase social, nivel económico y cultural etc.). De este modo, se verán obligados a razonar en términos generales o universales, de una manera totalmente imparcial, en cuanto resulta imposible todo cálculo utilitarista por parte de los participantes acerca de las ventajas particulares que les reportaría la elección de uno u otro principio de justicia (Rawls, 1993, p. 163 y ss).

Lo interesante, pues, es que el "velo de la ignorancia" constituye una condición indispensable para garantizar la racionalidad de la deliberación y de sus resultados ${ }^{9}$. $\mathrm{Y}$, por cierto, no deja de resultar significativo que entre los hechos particulares que Rawls expresamente hurta del conocimiento del individuo estén sus características biológicas y también sus rasgos psicológicos - entre los cuales menciona específicamente la aversión al riesgo o la tendencia al pesimismo o al optimismo -, en cuanto considera que se trata de factores que pueden menoscabar la racionalidad de sus decisiones. Aunque aquí, en la posición original, recordemos, estamos hablando de una decisión colectiva que versa sobre la elección de los principios de justicia que determinarán la distribución social de derechos y deberes, no de una

\footnotetext{
${ }^{9}$ Nos encontramos, así, dentro de la cartografía de la ignorancia trazada por Garzón Valdés (1999, p. 137), ante una "ignorancia conjetural" dirigida a promover la imparcialidad en un contexto de incertidumbre.
} 
decisión individual acerca del ejercicio de un determinado derecho. Esto es, nos encontramos en el nivel de la pregunta acerca de la justificación racional de un determinado derecho y no en el de la racionalidad en el ejercicio de ese derecho.

Pero, llegados a este punto, podemos aceptar el juego rawlsiano y preguntarnos si en su modelo puede encontrar fundamentación racional el reconocimiento de un derecho a no recibir información genética. Como sabemos, el propio Rawls indica que en cualquier momento una o más personas pueden colocarse en la posición original simplemente razonando conforme a las restricciones apropiadas, es decir, conforme a las restricciones exigidas por el velo de la ignorancia para razonar de manera imparcial. En este sentido, situándonos en la posición original, en la que cada participante conocería hechos generales tales como la importancia del factor genético en el desarrollo de enfermedades futuras, la posibilidad de acceder a esa información genética y el variable impacto que el conocimiento de dicha información puede tener sobre la personalidad de cada sujeto, pero ignoraría los hechos particulares acerca de su propia constitución genética, sus circunstancias personales y familiares, su proyecto de vida, su concepción del bien y sus rasgos psicológicos, habríamos de preguntarnos: ¿es racional aceptar la existencia de un derecho del individuo a no conocer sus datos genéticos o no?

Parece que, situados ante tal hipótesis, la aceptación de ese derecho es la alternativa más racional: desconociendo cada participante en la deliberación cuáles son sus planes de vida y sus concepciones acerca de lo que constituye una vida valiosa, si posee o no desórdenes genéticos y - en caso de poseerlos - cómo se vería afectada su personalidad por el conocimiento de los mismos, es razonable pensar que acordarían aceptar la posibilidad de que cada individuo tuviera el derecho a decidir si desea recibir o no su información genética. Especialmente si tenemos en cuenta la regla maximin que según Rawls determina la elección racional en estas condiciones de incertidumbre: existiendo diversas alternativas posibles, el sujeto que actúa racionalmente adoptará aquella cuyo peor resultado sea superior al peor resultado de las restantes (Rawls, 1993, p. 181). Es decir, enfrentado a la posibilidad de padecer algún desorden genético cuyo conocimiento podría tener un impacto negativo sobre su personalidad y sus relaciones familiares, el sujeto racional preferirá la alternativa que le permitirá, en su caso, decidir si recibe o no dicha información frente a aquella que no le permitirá no recibirla. Además, creo que ésta es la opción 
más coherente con el primer principio de justicia rawlsiano, que prescribe la extensión máxima de la libertad de todos: "cada persona ha de tener un derecho igual al esquema más extenso de libertades básicas iguales que sea compatible con un esquema semejante de libertades para los demás" (Rawls, 1993, p. 82).

Por tanto, desde la óptica del modelo rawlsiano de fundamentación de los derechos, el reconocimiento del derecho a no recibir información genética parece representar la opción más racional y la que otorga un contenido más amplio a la autonomía del individuo. No obstante, como señalaba anteriormente, debemos distinguir entre el debate sobre la racionalidad de la justificación del derecho y el debate sobre la racionalidad en el ejercicio del derecho. Es indudable que el reconocimiento de un derecho puede estar racionalmente fundado y, sin embargo, el sujeto puede realizar un ejercicio irracional del mismo: pocos discutirán que el reconocimiento, por ejemplo, de la libertad de expresión se halla racionalmente justificado, pero ello no obsta a que pueda hacerse un ejercicio irracional de dicha libertad. $Y$ el hecho de que el derecho pueda ser ejercido de manera irracional no incide en la justificación racional de su reconocimiento. Es cierto, no obstante, que ambas cuestiones pueden estar ligadas en la medida en que resultaría imposible justificar racionalmente la existencia de un derecho cuyo ejercicio fuera inherentemente irracional. $Y$ este es precisamente el principal argumento que, desde un punto de vista filosófico, se ha esgrimido contra el reconocimiento del derecho a no saber los datos genéticos: la renuncia a conocer esta información constituye una actitud irracional en cuanto imposibilita adoptar decisiones racionales ${ }^{10}$. Entonces, debemos preguntarnos: ¿es siempre esta renuncia una decisión irracional?

Para dar respuesta a esta pregunta el modelo rawlsiano también nos puede ayudar. Hemos visto cómo la discusión en la posición original versa únicamente sobre la elección de los principios de justicia que han de regir la distribución social de los derechos y deberes. Pero una vez consensuados los principios y asignados derechos y deberes, el velo de la ignorancia se levanta, compareciendo cada individuo en su

\footnotetext{
10 Esta es la posición de D. Ost (1984) para quien la racionalidad constituye una condición imprescindible de la autonomía. Desde esta perspectiva, puesto que la autonomía es la base para la adscripción de derechos, la decisión del individuo de rehusar la información - en cuanto constituye un acto irracional - equivale a "afirmar ipso facto que no es autónomo, es decir, que no es un sujeto portador de derechos" (p. 304). En consecuencia, Ost concluirá que el individuo no sólo tiene el derecho sino también el deber de ser informado, en cuanto la autonomía es un estatus irrenunciable ( $p$. 309).
} 
singularidad. A partir de esta singularidad, cada individuo es libre para perseguir su propio proyecto racional de vida en el marco institucional diseñado. $Y$ es este proyecto particular el que determinará su concepción del bien, en cuanto implica la elección de determinados fines o propósitos vitales, una determinada valoración de los intereses y valores en disputa, y, en definitiva, una determinada concepción acerca de lo que constituye una vida valiosa. Enfrentado, pues, un individuo a la alternativa de recibir o no determinada información genética, la decisión de ignorarla ¿es necesariamente irracional? Parece que el juicio acerca de la racionalidad de tal decisión no puede realizarse sin tener en cuenta el proyecto de vida del sujeto y sus circunstancias particulares. Desde luego, sería cuestionable la racionalidad de la decisión de ignorar hechos o informaciones que podrían resultar relevantes para llevar a cabo el proyecto de vida elegido. Pero la selección de qué hechos o informaciones han de ser considerados relevantes sólo puede hacerse desde los propios presupuestos de ese proyecto particular y de la concepción del bien que lleva aparejada. Y, por tanto, se trata de una decisión que únicamente puede ser realizada por el propio individuo ${ }^{11}$. Del mismo modo que éste es el único legitimado para ponderar el previsible beneficio de la recepción de la información genética con el impacto psicológico que ese conocimiento tendría sobre su personalidad y, en consecuencia, sobre su misma capacidad para desarrollar sus planes de vida de la forma que estima valiosa ${ }^{12}$.

En definitiva, desde la teoría de la justicia rawlsiana, la decisión de ignorar información genética puede hallarse racionalmente justificada, en la medida que el reconocimiento de dicho derecho contribuye a maximizar el derecho de todo individuo a disfrutar de aquella esfera más amplia de libertad que sea compatible con la igual libertad de los demás. Y creo que este reconocimiento es también la posición más coherente con los presupuestos de la tradición liberal que Rawls quiere revitalizar, en

\footnotetext{
${ }^{11}$ El individuo podría optar así por extender un "velo de la irrelevancia" sobre aquellas circunstancias que no contribuyeran a la mejor realización de su proyecto vital o que no resultaran coherentes con su concepción del bien. Actuando de esta manera, el sujeto estaría realizando, como señala E. Garzón Valdés (1999, p. 135).

${ }^{12}$ Sobre todo teniendo en cuenta que, tal como afirma L. Sagols (2007, p. 492), en la decisión de saber o ignorar no sólo ha de tenerse en cuenta el aspecto puramente intelectual, ya que están involucrados también aspectos psicológicos, emotivos y referentes a la situación concreta del individuo, muy complejos. De manera que en el saber genético "el destino entero, así como el conjunto de las capacidades se encuentra comprometido y, lejos de propiciar siempre una mejor planeación de la vida, puede ocurrir lo contrario".
} 
cuanto supone otorgar una mayor autonomía y capacidad de decisión racional al individuo. Desde esta perspectiva, el derecho a no saber vendría a configurar un ámbito de autonomía o autodeterminación del individuo en virtud del cual éste gozaría de libertad para decidir si desea - y en qué medida - o no recibir determinada información genética. De manera que, como argumenta R. Andorno, el reconocimiento de dicho derecho, lejos de suponer un regreso al paternalismo médico, constituye una expresión del principio de autonomía, entendida en un sentido amplio, como libertad del individuo para realizar sus propias elecciones con respecto a la información (Andorno, 2004, p. 436) ${ }^{13}$.

En este sentido, me parece que podríamos llegar a una conclusión similar si utilizamos el conocido principio liberal del daño de Mill, en virtud del cual cada individuo ha de tener el derecho a actuar conforme a su propia voluntad en tanto sus acciones no supongan un perjuicio para los demás. De acuerdo con dicha máxima, evitar el daño de terceros es, pues, la única razón que justificaría la interferencia en la libertad de actuación del individuo. Por el contrario, la apelación a su propio bien, físico o moral, no constituye una razón justificativa para interferir en sus decisiones, aun cuando éstas puedan ser consideradas por otros agentes como incorrectas o irracionales, puesto que en la esfera de actuación que le concierne únicamente a él es - debe ser - soberano (Mill, 1988, p. 65-66). Desde este punto de vista, aplicando dicho principio al derecho a no recibir información genética, tan paternalista sería no permitir el conocimiento de la misma como imponerlo, en cuanto el individuo es el único que puede decidir acerca de cuestiones como su felicidad, sus planes de vida o los riesgos que está dispuesto a asumir ${ }^{14}$.

\footnotetext{
${ }^{13}$ También hace descansar en el principio de autonomía el derecho a no saber P. Nicolás Jiménez (2006, p. 129), quien lo vincula con la protección de la intimidad. Y creo que idéntico fundamento recaban aquellas posiciones que lo enmarcan en el contenido de un derecho de "autodeterminación física", "autodeterminación informativa" o "autodeterminación genético-informativa", como hacen, respectivamente, Y. Gómez Sánchez (2011, p. 595); "el derecho de autodeterminación física como derecho de cuarta generación" (Gómez Sánchez, 2011, p. 233); y L. Sagols (2007, p. 492). Entendido el derecho a no saber como una expresión del principio de autonomía, su ejercicio requiere la manifestación por parte del sujeto de su deseo de no ser informado, quedando así eximido el profesional sanitario de su deber de informar.

${ }^{14}$ Para una defensa del derecho a no saber fundada específicamente en el principio del daño de Mill, ver M. Strasser (1986).
} 


\subsection{El derecho a no saber frente al derecho de familiares a acceder a la información genética.}

No obstante, podríamos preguntarnos si el ejercicio del derecho a no saber puede ocasionar un daño a terceras personas, lo que contravendría tanto el principio del daño de Mill como, específicamente, el principio bioético de no maleficencia. La cuestión resulta pertinente porque otra de las objeciones principales que se ha opuesto a aquel es que el individuo que renuncia a recibir la información estaría actuando insolidariamente y olvidando su deber de responsabilidad hacia otras personas, al impedir que los familiares tengan conocimiento de una información que podría ser beneficiosa para ellos.

Antes de responder a esta pregunta es necesario, sin embargo, despejar la cuestión de la titularidad de los datos genéticos. En este sentido, ya se comentó anteriormente que, en atención a la doble naturaleza, personal y familiar, de la información genética se ha defendido incluso por parte de algún sector doctrinal la titularidad familiar de los datos genéticos de cualquiera de sus miembros. Es evidente que, si esto fuera así, no cabría siquiera plantear la posibilidad de este conflicto entre el derecho del sujeto sometido a las pruebas genéticas y los derechos de sus familiares - al menos en los términos en que aquí se hace -, en la medida en que cualquiera de estos podría acceder en cualquier circunstancia al conocimiento de "sus" datos. Sin embargo, el hecho de que los datos genéticos del individuo tengan, sin duda, una dimensión familiar - e incluso grupal, en cuanto algunos son patrimonio común del grupo étnico - no hace que aquellos sean objeto de una titularidad compartida. Como señala P. Nicolás, de la misma manera que se reconoce como derecho de la personalidad el derecho a la intimidad familiar, que corresponde como derecho individual a cada miembro de la familia y no a ésta como sujeto, también la titularidad de los datos genéticos corresponde a cada individuo aunque el objeto de protección del derecho individual venga constituido por un ámbito a la vez propio y compartido (Nicolás Jiménez, 2006, p. 101). De manera que la existencia de aquella dimensión familiar no autoriza sin más a un miembro de la familia a inmiscuirse en el derecho de otro, aunque sin duda esa singularidad de la información genética habrá de ser tenida en cuenta a la hora de establecer límites al derecho individual.

Puestas así las cosas, por tanto, ¿puede considerarse que la persona que ejerce su derecho a no conocer sus datos genéticos causa un daño a sus familiares? 
Desde luego, parece desproporcionado considerar, con carácter general, que la decisión de un individuo de no conocer sus propios datos genéticos pueda constituir un daño para sus familiares, aun cuando tales datos puedan resultar de interés para ellas. De hecho, es posible que estas personas ni siquiera deseen acceder a esa información, que no han solicitado, por lo que una actitud imprudente en esta cuestión podría incluso ocasionar interferencias indeseadas en la libertad de los terceros ${ }^{15}$. Además, en última instancia, la decisión del sometido a los test genéticos de no conocer sus datos no impide que cualquier otro familiar biológico interesado en la información se someta a las pruebas genéticas necesarias para su obtención. En este sentido, parece que el deber de cuidado y de responsabilidad ha de pesar antes sobre uno mismo que sobre los demás. Sin duda, las actitudes solidarias y responsables son valiosas desde un punto de vista ético, pero no cabe imponer en virtud de las mismas al individuo un deber jurídico de conocer, violentando su autonomía personal.

No obstante, es cierto que en determinados casos pueden producirse situaciones complejas y problemáticas, en las que será preciso tener debidamente en cuenta y ponderar los derechos de todos los sujetos afectados. Pero esto no es nada distinto de lo que ocurre en el ejercicio de cualquier otro derecho, en la medida en que ninguno de ellos tiene un carácter absoluto, debiendo siempre conjugarse y armonizarse con otros derechos en conflicto. No estamos ya, por tanto, ante un problema de justificación del derecho a no saber sino de definición de sus límites.

\footnotetext{
${ }^{15}$ Uno de los aspectos más problemáticos que plantea el ejercicio del derecho a no saber tiene que ver precisamente con la dificultad de determinar los criterios de actuación a seguir en aquellos casos en que el individuo no ha decidido si desea o no conocer la información, como sucede en este caso con los familiares de la persona sometida a las pruebas genéticas. Esto es, ¿debe revelarse o no la información genética a una persona que no ha manifestado su voluntad al respecto? El problema es difícil de resolver en la práctica porque en estos casos no cabe preguntar a la persona en cuestión si desea conocer los riesgos detectados para su salud, pues el mero hecho de realizar la pregunta implica revelar la esencia de la información. En opinión de G. T. Laurie (1999), este dilema no puede resolverse únicamente desde el principio de autonomía: la autonomía exige elección, pero ¿cómo actuar cuando una persona no ha podido elegir? Para colmar ese vacío propone fundar el derecho a no saber, antes que en el principio de autonomía, en el de privacidad, que vendría a garantizar la inaccesibilidad de aquel dominio, tanto físico como psicológico, del individuo que lo mantiene separado de los demás y en el que sus intereses son prioritarios. De este modo, aun cuando una persona no haya podido expresar si desea o no conocer la información genética, habrá de respetarse ese espacio de privacidad. Desde esta perspectiva, pues, existiría un deber prima facie de no informar a quien no ha podido manifestar su voluntad. El enfoque de Laurie operaría así una inversión con respecto a la presunción derivada del principio de autonomía, en virtud del cual, ante la ausencia de manifestación de voluntad, el profesional sanitario se hallaría en la obligación de informar (Laurie, 2000; Laurie, 2004).
} 
Desde esta perspectiva podemos cuestionarnos, pues, en qué circunstancias el derecho de los familiares a conocer los datos genéticos del sujeto analizado habría de prevalecer sobre el derecho de éste a ignorarlos. Aunque si analizamos esta cuestión, veremos que atañe fundamentalmente a la determinación de los límites del derecho a la intimidad y a la confidencialidad del sujeto sometido a las pruebas genéticas, y sólo de manera indirecta a la delimitación de su derecho a no saber. En efecto, la cuestión fundamental a determinar es si existen determinadas situaciones en las que los familiares tienen derecho a conocer los datos genéticos de aquel, accediendo así a la esfera de su intimidad. Y sólo si la respuesta a esta pregunta es positiva, podría entonces entenderse limitado el derecho del individuo a no conocer sus datos genéticos (aunque no necesariamente, ya que cabría plantearse aún si la obligación de trasladar la información a los familiares recae sobre aquel o directamente sobre el profesional sanitario).

Respondiendo a la cuestión, el Convenio Europeo de Derechos Humanos y Biomedicina establece la posibilidad de que, en determinadas situaciones excepcionales, las legislaciones nacionales puedan imponer restricciones al ejercicio del derecho a no saber cuando sea necesario para proteger tanto la propia salud del individuo (en virtud del artículo 10.3) como los derechos y libertades de terceros (en virtud del artículo 26.1). Más explícitamente aún, el Explanatory Report del Convenio afirma que "ciertos hechos relativos a la salud de una persona que ha expresado su deseo de no ser informada acerca de los mismos pueden ser de especial interés para terceros". En estos casos "la posibilidad de prevenir el riesgo para el tercero podría, en virtud del artículo 26, justificar la prioridad del derecho de aquel sobre el derecho a la intimidad del paciente y, a resultas de ello, de su derecho a no saber" (Consejo de Europa, 1996). Es preciso tener en cuenta, sin embargo, que estas disposiciones se refieren al ámbito de la información sobre la salud en general, y no específicamente al de la información genética, en el cual las garantías de protección han de ser especialmente exigentes. En este sentido, la Declaración Universal sobre el Genoma Humano y los Derechos Humanos, aplicable específicamente a la información genética, aunque es muy parca en relación a este problema, sí señala que la 
interferencia en el derecho a la intimidad - y, en consecuencia, en el derecho a no saber - ha de obedecer en todo caso a "razones imperiosas"16.

A partir de este marco, la doctrina ha intentado concretar estos supuestos excepcionales que justificarían la revelación de los datos genéticos del sujeto analizado a sus familiares, existiendo prácticamente un consenso generalizado acerca de que, en todo caso, aquellos sólo podrían referirse a situaciones que supusieran un serio riesgo para su salud (Romeo Casabona, 2002). En este sentido se ha señalado que el derecho a la intimidad debería ceder cuando concurren las siguientes circunstancias: existe una alta probabilidad de que los familiares (incluidos los hijos futuros, en cuyo caso habría de informarse a la pareja del sujeto) padezcan la patología detectada, ésta comporta un riesgo grave para su salud o su vida, existen medidas preventivas o terapias sin importantes efectos secundarios, es baja la probabilidad de que los familiares sean diagnosticados sin la información de su pariente y el perjuicio que se ocasiona a éste no es excesivo (Buchanan, 2000, p. B21). Dadas estas condiciones, en consecuencia, el derecho del individuo a no saber habría de ceder ante el derecho de los familiares a conocer una información que resulta vital para su salud ${ }^{17}$. De manera que el profesional sanitario estaría en la obligación de proporcionar dicha información a aquel, pese a su expreso deseo de ignorarla (e incluso en la de suministrarla directamente a los familiares si su paciente se negara reiteradamente a hacerlo él mismo) (Nuffield Council, 1993, p. 43). Aunque, como se ha mencionado anteriormente, la solución a este conflicto de derechos no ha de pasar necesariamente por la derrota del derecho a no saber. En este sentido es de

\footnotetext{
${ }^{16}$ En España, la Ley 14/2007, de 3 de julio, de investigación biomédica, sólo permite esa interferencia en la intimidad genética del individuo cuando "sea necesaria para evitar un grave perjuicio para su salud o la de sus familiares biológicos" (art. 4.5). Se establece así una exigencia superior a la prevista con carácter general en relación a la información sanitaria en la Ley $41 / 2002$, de 14 de noviembre, básica reguladora de la autonomía del paciente y de derechos y obligaciones en materia de información y documentación clínica, en virtud de la cual "la renuncia del paciente a recibir información está limitada por el interés de la salud del propio paciente, de terceros, de la colectividad y por las exigencias terapéuticas del caso" (art. 9.1).

17 Una posición mucho más restrictiva del derecho a no saber es la defendida por R. Vázquez (2007), en virtud de la cual aquel habría de ceder no sólo ante los intereses de los familiares en conocer los datos genéticos de su pariente sino también ante los de la comunidad en general, en virtud de un deber de solidaridad. Desde esta perspectiva, el individuo no sólo no podría reclamar un derecho a la ignorancia cuando su información genética reportase beneficios significativos a la comunidad sino que se hallaría incluso sujeto a un deber positivo de someterse a la realización de estudios e investigaciones genéticas en beneficio de la comunidad. Nos parece que esta posición es criticable por cuanto prácticamente vacía de contenido el derecho a no saber, aunque sin duda ese vaciamiento es coherente con el punto de partida del autor, para quien "el derecho a no saber, lejos de incrementar el valor de la autonomía personal, tiende a degradarlo" (Vázquez, 2007, p. 345).
} 
reseñar la solución arbitrada por la ley española de investigación biomédica, que dispone que, cuando la información genética de una persona que ha expresado su deseo de no conocerla sea necesaria para evitar un grave perjuicio para su propia salud o la de sus familiares, el médico informará a un familiar próximo o a un representante, intentando conciliar así los distintos intereses en juego sin sacrificar ninguno de los derechos de las partes.

\subsection{La autonomía individual, entre la libertad y el determinismo: el Derecho como instancia mediadora.}

Con todo, el reconocimiento de este derecho a no saber no constituye el único mecanismo a través del cual el Derecho tutela la ignorancia de ciertos datos personales en el ámbito de la información genética. En este sentido, podemos encontrar que en determinados supuestos el ordenamiento jurídico va más allá de la simple permisión del no-conocimiento para imponer un genuino "deber de no saber". Incluso aunque este deber de ignorar pueda suponer privar a una persona del conocimiento de algo tan personalísimo como su propia identidad biológica. Así sucede cuando - como, por ejemplo, en el caso del Derecho español - se prohíbe el acceso del individuo nacido mediante técnicas de reproducción asistida con donante/s de gametos al conocimiento de la identidad de su progenitor biológico. Mediante la imposición de este deber de no saber se priva, pues, de manera excepcional, al individuo nacido mediante estas técnicas del derecho a la determinación de su filiación biológica ${ }^{18}$. De este modo, el Derecho ha optado por otorgar prioridad a la voluntad responsable de los sujetos implicados en el proceso de reproducción frente al principio de la verdad biológica en la construcción de las relaciones paternofiliales $^{19}$. Prioridad de la libertad sobre la naturaleza, en una muestra de la autonomía del Derecho frente a las demandas de sujetar el orden de las relaciones jurídicas a las exigencias de un nuevo ius naturae, esta vez de cuño genético.

\footnotetext{
${ }^{18}$ Derecho que es reconocido, sin embargo, en cualquiera del resto de supuestos en los que no existe coincidencia entre los padres biológicos y legales (adopción, paternidad desconocida, no reconocida o no atribuida, simulación de parto o suplantación de la identidad del hijo).

${ }^{19}$ Ya la ley española sobre técnicas de reproducción asistida de 1988, hoy derogada, advertía en su Exposición de motivos de las profundas implicaciones que la generalización de estas técnicas acarrearía para la concepción tradicional de la relación paterno-filial: "pueden la maternidad y la paternidad biológicas serlo también legales, educacionales o de deseo, y en tal sentido, es importante valorar cuál es la más humanizada, la más profunda en relación con el hijo".
} 
Y es que, más allá de los debates concretos sobre la conveniencia o no del acceso del individuo a determinada información genética, estos no constituyen sino el síntoma de un desafío más profundo, en cuanto aquel conocimiento parece comprometer de raíz los presupuestos filosóficos y antropológicos sobre los que se asienta nuestra justificación de los derechos fundamentales. La filosofía de los derechos se ha erigido sobre el presupuesto de la autonomía del sujeto y de la afirmación de su libre albedrío, en oposición a cualquier clase de determinismo, ya sea éste de carácter naturalista, teológico, histórico, económico, etc. La libertad es incompatible con la necesidad. Sin embargo, el desarrollo y la progresiva generalización de las técnicas genéticas, con sus extraordinarias e impredecibles potencialidades para desvelar las claves ocultas de nuestra condición biológica, tanto pasada como futura, nos plantea la situación de un individuo sometido dramáticamente al vértigo de esa profunda tensión entre las potencias de la voluntad y de la naturaleza humana, entre la libertad y la determinación ${ }^{20}$.

El acceso creciente a una información genética cada vez más completa nos coloca ante la perspectiva de un individuo capaz de transcender la temporalidad y descifrar en buena medida las páginas, ya escritas, de su existencia. Es cierto que el determinismo genético - al menos a día de hoy - no puede considerarse un hecho absoluto. Como nos recuerda L. Sagols, si bien existen enfermedades monogenéticas y ciertos rasgos físicos que dependen de un solo gen, de manera que su desarrollo responde a una causalidad lineal directa, y, por ende, resultan fatales, la mayoría de las propiedades que nos conforman responden a una causalidad más compleja, en la que intervienen también factores ambientales, lo que comporta un margen de indeterminación y variación. Por ello, "aunque no puede negarse el determinismo, éste ha de ser restringido a su ámbito limitado y ha de enfatizarse el hecho de que, en general, estamos sujetos a determinaciones o propensiones genéticas" (Sagols, 2007 , p. 490). Pero, con todo, el extraordinario desarrollo del conocimiento y las técnicas genéticas nos aproxima a una perspectiva que nos asomaría peligrosamente a la visión de aquel demonio de Laplace capaz de acceder a un universo atemporal, transparente y previsible, en el que tanto el futuro como el pasado estarían presentes

${ }^{20}$ Como afirma L. Wittgenstein (2009, par. 5.1362, p. 73), "la libertad de la voluntad consiste en que acciones futuras no pueden conocerse ahora". 
ante sus ojos, pero aplicada esta vez a la propia existencia de cada individuo (Laplace, 1996, p. 25).

De este modo, la utopía ilustrada de la libertad, con su confianza optimista en la plena capacidad del individuo para controlar su destino, se ve amenazada por la distopía científica de la determinación genética. En este sentido, no podemos dejar de prestar atención a la advertencia que ya el Danish Council of Bioethics hacía en su informe Ethics and Mapping the Human Genome (1993) acerca del riesgo, corroborado por diversos estudios empíricos, de "morbidificación" que comporta la revelación de la información genética: la importante carga psicológica que el conocimiento del serio riesgo de padecer una enfermedad grave e incurable supone para el individuo termina por convertir a éste en muchas ocasiones en una "falling victim", una víctima rendida a un destino que considera ineludible.

Si en la posición original de Rawls el sujeto, ubicado en una dimensión hipotética y atemporal, quedaba privado del conocimiento de todas sus circunstancias particulares para evitar que dicho saber interfiriera en la racionalidad de sus decisiones, la genética nos plantea la posibilidad - cada vez menos hipotética - de un individuo conocedor de buena parte de los designios de su existencia biológica desde la concepción hasta la tumba. Y esta variación en las condiciones de partida sin duda supone también una alteración tanto de la percepción de nuestra propia libertad como de las condiciones de racionalidad en las que se desenvuelven nuestras deliberaciones y la toma de nuestras decisiones. Así las cosas, tal vez haya que acordar con Ernesto Garzón Valdés que la ignorancia es, en muchas ocasiones, "la condición necesaria para poder transitar por este mundo con una buena dosis de libertad y de esperanza"21.

En definitiva, el conocimiento genético nos aboca a la consciencia de un universo más complejo en el que la causalidad y la libertad (junto con el azar)

\footnotetext{
${ }^{21}$ Nos adentramos así en los territorios de la "ignorancia querida", que podría ser entendida como una forma laudable de autoengaño. Justamente un caso paradigmático de la misma es, en opinión del autor, el relativo a las cuestiones vinculadas con la aceptación del determinismo. Así como preferimos "ignorar si el determinismo es verdadero, también en nuestra vida cotidiana hay cosas que preferimos no saber: todos sabemos que alguna vez moriremos, pero posiblemente nuestra vida sería mucho menos llevadera si desde pequeños supiéramos el día y la hora exacta de nuestra muerte". De este modo, "la ignorancia querida nos envuelve en una niebla protectora de la que no podemos prescindir mientras seamos como somos, es decir, seres vulnerables a las reacciones de los demás y a la verdad desnuda que no pocas veces nos ofende, portadores de esperanzas, supuestamente libres, agentes morales imperfectos, ni ángeles ni maquinas, racionales pero vacilantes e inseguros en nuestras conjeturas" (Garzón Valdés, 1999, p. 145-146).
} 
interactúan en la conformación del propio sujeto y de su destino. Y el Derecho, constituido en instancia mediadora, habrá de buscar compromisos y equilibrios delicados - y casi siempre inestables - entre ambas fuerzas mediante la oportuna administración del saber y de la ignorancia, erigiendo un entramado de velos más o menos tupidos en aras a la protección de la autonomía de los individuos para construir sus propios proyectos vitales en un contexto en el que sus relaciones personales y familiares se articulan crecientemente desde la primacía de la voluntad sobre la naturaleza.

\section{Referências}

ANDORNO, R. The right not to know: an autonomy based approach. Journal of Medical Ethics, 30:435-440, 2004.

BUCHANAN, A. An Ethical Framework for Biological Samples Policy. En NATIONAL BIOETHICS ADVISORY COMMISSION. Research Involving Human Biological Materials: Ethical Issues and Policy Guidance, vol. II. Mariland: National Bioethics Advisory Commission, 2000.

CHADWICK, R. The Philosophy of the Right to Know and the Right not to Know. En CHADWICK, R; LEVITT, M. y SHICKE, D. (Eds.), The Right to Know and the Right not to Know. Aldershot: Ashgate, 1997.

CONSEJO DE EUROPA. Explanatory Report to the Convention on Human Rights and Biomedicine, 1996, par. 70 (http://conventions.coe.int/Treaty/en/Reports/Html/164.htm).

GARZÓN VALDÉS, E. Algunas reflexiones sobre la ignorancia. Isonomía, (11):129148, 1999.

GÓMEZ SÁNCHEZ, Y. El derecho de autodeterminación física como derecho de cuarta generación. En: BRENA, I. (Coord.), Panorama internacional en salud y Derecho. Mexico : Instituto de Investigaciones Jurídicas de la UNAM, 2007.

GÓMEZ SÁNCHEZ, Y. Derecho a no saber. En: ROMEO CASABONA, C. M. (Dir.). Enciclopedia de Bioderecho y Bioética, Tomo I. Granada: Comares, 2011.

KANT, I. Respuesta a la pregunta: ¿Qué es la llustración? En: AA. VV. ¿Qué es Ilustración?, trad. de A. Maestre y J. Romagosa. Madrid: Tecnos, 1989.

KOSSEIM, P. y JOSPE, D. La puesta en práctica del consentimiento en el contexto de los biobancos. En: BUISÁN, L. y SÁNCHEZ, A. (Coord.), Intimidad, confidencialidad y protección de datos de salud. Navarra: Civitas, 2011.

LAPLACE, P. S. Ensayo filosófico sobre las posibilidades, trad. de P. Castrillo, Barcelona: Altaya, 1996.

LAURIE, G. T. In Defence of Ignorance: Genetic Information and the Right Not to Know. European Journal of Health Law, (6):119-132, 1999. 
LAURIE, G. T. Protecting and Promoting Privacy in an Uncertain World: Further Defences of Ignorance and the Right Not to Know. European Journal of Health Law, (7):185-191, 2000.

LAURIE, G. T. A Response to Andorno. Journal of Medical Ethics, 30:439-440, 2004.

MACKLIN, R. Privacidad y confidencialidad en investigación biomédica y del comportamiento. En: BUISÁN, L. y SÁNCHEZ, A. (Coord.). Intimidad, confidencialidad y protección de datos de salud. Navarra: Civitas, 2011.

MALEM, J. Estudios de ética jurídica. México: Fontamara, 2005.

MILL, J. S. Sobre la libertad, trad. de P. Azcárate. Madrid: Alianza Editorial, 1988.

NICOLÁS JIMÉNEZ, P. La protección jurídica de los datos genéticos de carácter personal, Cátedra de Derecho y Genoma Humano. Bilbao-Granada: Editorial Comares, 2006.

NUFFIELD COUNCIL ON BIOETHICS. Genetic Screening. Ethical issues. London: Nuffield Council of Bioethics, 1993.

OST, D. The 'Right' Not to Know. The Journal of Medicine and Philosophy, 9(3):301312, 1984.

RAWLS, J. Teoría de la Justicia, trad. de M. D. González. Madrid: Fondo de Cultura Económica, 1993.

RODOTÀ, S. Protection de la vie privée. En: HOTTOIS, G. y NISSA, J. (Dir.). Nouvelle encyclopédie de bioéthique. Bruxelles : De Boeck, 2001.

ROMEO CASABONA, C. M. Los genes y sus leyes: el derecho ante el genoma humano, Bilbao-Granada: Comares, 2002.

SAGOLS, L. Responsabilidad bioética ante la información genética. En: BRENA, I. (Coord.), Panorama internacional en salud y Derecho. Mexico: Instituto de Investigaciones Jurídicas de la UNAM, 2007.

STRASSER, M. Mill and the Right to Remain Uninformed. The Journal of Medicine and Philosophy, 11(3):265-278, 1986.

VÁZQUEZ, R. Opacidad y transparencia. En torno a la información genética. En: BRENA, I. (Coord.). Panorama internacional en salud y Derecho, México: Instituto de Investigaciones Jurídicas de la UNAM, 2007.

WITTGENSTEIN, L. Tractatus logico-philosophicus, trad. de J. Muñoz e I. Reguera. Madrid: Gredos, 2009. 